\title{
A multiple-channel cochlear implant: An evaluation using closed-set spondaic words
}

\author{
By G. M. Clark, Y. C. Tong and L. F. A. Martin \\ (Melbourne, Australia)
}

\section{Introduction}

Two post-lingually deaf patients with total hearing losses have had help in communicating, using a multiple-channel cochlear implant(Tong et al., in press; Tong and Clark, 1980). Single-channel implants have also been shown to be of value (House et al., 1976; Fourcin et al., 1979). As the multiple-channel device, however, requires an intra-cochlear electrode array it was considered worthwhile comparing the closed-set spondaic word test results obtained from our patients with those from intra-cochlear single-channel implants (Bilger et al., 1977).

Using the multiple-channel device speech was processed by extracting the voicing frequency and energy, and the frequency and energy of the dominant spectral peak in the mid-frequency range. The parameters for voicing determined the rate of stimulation for all electrodes, and the parameters for the dominant spectral peak in the mid-frequency range determined the site of electrode stimulation and current level. On the other hand, with the single-channel implant (House et al., 1976) the speech wave amplitude modulated a $16 \mathrm{kHz}$ carrier frequency, and this in turn stimulated the auditory nerve.

\section{Methods}

Sixteen spondaic words, having equal intelligibility to normal hearing subjects, were used. Lists, with each word represented five times and selected at random, were prepared. Each 80 -word list was presented before and after training in word identification, and with a pre-recorded and 'live' voice. Training consisted of rehearsing the words for half an hour.

The words used in the test were recorded on a tape-recorder by a female speaker with a British accent. The words in the 'live' presentation were given by the same speaker in a room with no sound treatment, and precautions were taken to ensure that the patient could not lipread the speaker.

\section{Results}

The results of the study are shown in Table I. From this it can be seen that, before training, the scores for patients $\mathrm{MC}-1$ and $\mathrm{MC}-2$ were 45 per 
TABLE I

CLOSED-SET SPONDAIC WORD TEST

MULTIPLE-CHANNEL COCHLEAR IMPLANT ALONE

\begin{tabular}{lll}
\hline & Patient & Result \\
\hline $\begin{array}{c}\text { Before training } \\
\text { Pre-recorded }\end{array}$ & MC-1 & \\
& MC-2 & $55 \%$ \\
Live & MC-1 & $52 \%$ \\
Mfter training & MC-2 & $52 \%$ \\
Pre-recorded & MC-1 & $52 \%$ \\
Live & MC-2 & $53 \%$ \\
& MC-1 & $60 \%$ \\
\end{tabular}

cent and 52 per cent for pre-recorded presentations, and 52 per cent and 52 per cent for 'live' voice presentations. After training the scores were 53 per cent and 60 per cent for pre-recorded words, and 43 per cent for patient MC-1 for the 'live' voice test.

\section{Discussion}

In this study, the method of presenting the spondaic words was made as close as possible to that described by Bilger et al. (1977). The main difference was that in our study both patients had 80 words presented for each test condition, whereas in the study by Bilger et al. the patients received sets of words which varied in number from 20 to 50 .

TABLE II

\begin{tabular}{|c|c|c|}
\hline Treatment & $\%$ & Rank \\
\hline B & 4 & 1 \\
\hline B & 10 & $2^{1 / 2}$ \\
\hline B & 10 & $2^{1 / 2}$ \\
\hline B & 16 & 4 \\
\hline B & 18 & $5^{1 / 2}$ \\
\hline B & 18 & $51 / 2$ \\
\hline B & 20 & $7^{1 / 2}$ \\
\hline B & 20 & $7^{1 / 2}$ \\
\hline B & 21 & 9 \\
\hline A & 45 & 10 \\
\hline A & 52 & 11 \\
\hline
\end{tabular}

A-Multiple-channel cochlear implant (Tong et al., in press).

B-Single-channel cochlear implant (House et al., 1976, Bilger et al., 1977).

Sum of ranks of treatment $A$ is 21

$\mathrm{m}=2$

$\mathrm{n}=9$

$\mathrm{p}=0.025$ (single tail test) 
The mean score for the multiple-channel implant was 48.5 per cent, and the mean for the single-channel implant $15 \cdot 2$ per cent (Table II). When these were analysed statistically, the difference in results was significant at the 0.025 probability level (Table II). A Wilcoxon Rank Sum test was used, as the scores were in percentages.

This difference between the results was most probably due to more i. formation being provided about speech by the multiple-channel device. The advantages of multip'--channel electrical stimulation can be seen trom our previous studi, s, which have shown that the patients can experience a difference in vowel colour, which varies according to the position of the stimulating electrode, and is consistent with the place theory of frequency coding (Tong et al., in press). Furthermore, using this knowledge to design a speech processor which extracts the voicing frequency and energy, and the frequency and energy of the dominant spectral peak in the mid-frequency range it has been possible for the patient to understand some running speech using the implant alone, and when used in conjunction with lipreading they have been able to engage in almost normal everyday conversation. These findings have been confirmed using standard audiological tests which involve the presentations of nonsense syllables, open-set word lists and open-set sentence lists (Tong and Clark, 1980).

\section{Conclusion}

This study has shown that the results with a closed-set spondaic word test are significantly better for two patients receiving a multiple-channel cochlear implant (Tong et al., in press), than for a group of nine patients who had an intra-cochlear single-channel device (House et al., 1976; Bilger et al., 1977).

\section{Acknowledgements}

We would like to thank the Department of Productivity of the Australian Government, the National Health and Medical Research Council of A ustralia, and the Channel 10 Deafness Appeal, for providing financial support. We are indebted to Miss Betty Laby, Department of Statistics, University of Melbourne, for advice and help. We would like to thank Mr. P. Busby, Mr. J. Patrick, Dr. P. Seligman, Mr. P. Blamey, Mr. G. Cook, Mr. L. Cole, Mr. R. Walkerden and Miss J. Maher for their help.

\section{REFERENCES}

Bilger, R. C., Black, F. O., Hopkinson, N. J., Myers, E. N., Payne, J. L., Stenson, N. R., VEGA, A., and Wolf, R. V. (1977) The Annals of Otology, Rhinology and Laryngology, Supplement 38 . Vol. 86.

Fourcin, A. J., Rosen, S. M., Moore, B. C. J., Douek, E. E., Clarke, G. P., Dodson, H., and BANnister, L. H. (1979) British Journal of Audiology, 85, 13. 
House, W. F., Berliner, K., Crany, W., Graham, M., Luckey, R., Norton, N., Selters. W., Tobin, H., Urban, J., and Wenlex, M. (1976) The Annals of Otology, Rhinology and Laryngology, Supplement 27, Vol. 85 .

Tong, Y. C., Millar, J. B., Clark, G. M., Martin, L. F., Busby, P. A.. and Patrick, J. F. Journal of Laryngology and Otology; (In press).

Tong, Y. C.., and Clark, G. M. (1980) Proceedings of the Australian Physiological and Pharmacological Society, 11, No. 2, 201 p. 


\section{University Library}

\section{- M M N E R VA A gateway to Melbourne's research publications}

Minerva Access is the Institutional Repository of The University of Melbourne

Author/s:

Clark, Graeme M.;Tong, Y. C.;Martin, L. F.

Title:

A multiple-channel cochlear implant. An evaluation using closed-set spondaic words

Date:

1981

Citation:

Clark, G. M., Tong, Y. C., \& Martin, L. F. (1981). A multiple-channel cochlear implant. An evaluation using closed-set spondaic words. Journal of Laryngology and Otology, 95(5), 461-464.

Persistent Link:

http://hdl.handle.net/11343/28740 